\title{
Mulheres de sucesso no campo científico: uma análise de redes sociais
}

\author{
Polliane Trevisan Nunes' (iD 0000-0003-3919-3455 \\ Fernanda Wanderer' (iD 0000-0002- 8198-7104 \\ 'Universidade Federal do Rio Grande do Sul, Porto Alegre, RS, Brasil. \\ 90040-060. ppgedu@ufrgs.br
}

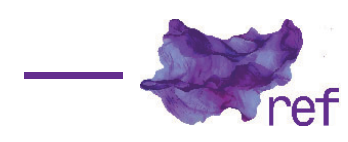

Resumo: Neste artigo, apresentamos resultados de uma pesquisa que examinou como as mulheres consideradas bem-sucedidas nas áreas da ciência e tecnologia narram a sua trajetória de sucesso. O material empírico constitui-se de reportagens veiculadas na rede social Facebook, obtidas no período de 2015 a 2018. Como aportes teóricos, foram utilizados estudos do pensamento de Michel Foucault. A análise mostrou que as trajetórias das mulheres de sucesso são marcadas pelo enfrentamento individual das dificuldades para consolidar uma carreira. Esse enfrentamento está vinculado aos mecanismos da racionalidade neoliberal presentes em nossa sociedade que posiciona o indivíduo como o único responsável por sua educação e qualificação profissional, esmaecendo a relevância dos processos coletivos e as ações do Estado como formas de garantir e sustentar a equidade de gênero nas áreas científicas.

Palavras-chave: Mulheres; campo científico; redes sociais; Michel Foucault.

Successful Women in The Scientific Field: An Analysis of Social Networks

Abstract: The article presents results from research that examined how women considered successful in science and technology narrate their successful trajectory. The empirical material consists of reports published on the social network Facebook obtained from 2015 to 2018. As theoretical contributions, studies of the thinking of Michel Foucault were used. Analysis has shown that the trajectories of successful women are marked by individual coping with the difficulties of consolidating a career. This confrontation is linked to the mechanisms of neoliberal rationality present in our society that positions the individual as solely responsible for their education and professional qualification, weakening the relevance of the collective and the actions of the state as ways of guaranteeing and sustaining gender equity in the scientific areas.

Keywords: Women; Scientific field; Social networks; Michel Foucault.

\section{Introdução}

No artigo, apresentamos resultados de uma pesquisa que objetivou analisar as formas pelas quais as redes sociais produzem a relação entre as mulheres e o campo científico. Em especial, o estudo consistiu em examinar como as mulheres consideradas bem-sucedidas nas áreas da ciência e tecnologia narram a sua trajetória de sucesso. Para isso, foram escrutinadas diversas reportagens sobre o tema que provêm de fontes compartilhadas em redes sociais no período de 2015 a 2018.

Na contemporaneidade, proliferam debates e reflexões sobre as relações de gênero em nossa sociedade, os quais se relacionam tanto às desigualdades entre homens e mulheres ainda presentes em diversos setores, quanto aos avanços já alcançados em prol da equidade de gênero. Muitas dessas conquistas emergem dos movimentos feministas que, desde a década de 1960, mobilizaram não só a geração de ações afirmativas, quanto a produção de teorizações 
e investigações relatando as histórias das mulheres e suas condições de trabalho, educação, saúde e participação política (Guacira Lopes LOURO, 2014).

Apesar de conquistas, em algumas áreas, ainda se fazem presentes desigualdades, como no campo científico. Tatiane Furukawa Liberato e Thales Haddas Novaes de Andrade (2018) destacam que na área da ciência e tecnologia a participação das mulheres é ainda menor que a masculina, sendo, às vezes, limitada e relegada a papéis marginais. Apoiando-se em pesquisas e dados estatísticos, os autores apontam que estudos têm sido realizados para refletir sobre as questões de gênero que marcam a área científica, como o menor número de mulheres no campo, a desigual oportunidade de acesso e permanência na carreira, bem como o desempenho inferior de mulheres em relação aos homens, o qual se manifesta, por exemplo, em menores taxas de publicação científica.

Em efeito, essas constatações já foram observadas e examinadas por estudiosas como Valerie Walkerdine (2007), Louro (2014) e Londa Schiebinger (2008; 2001), as quais destacam que há questões de ordem epistemológica que dificultaram - e ainda dificultam - o entendimento de que a ciência é um espaço e uma atividade para mulheres. Schiebinger (2001, p. 26) afirma que a maior contribuição do feminismo foi questionar a neutralidade do gênero na ciência, "revelando que valores geralmente atribuídos às mulheres foram excluídos da ciência e que desigualdades de gênero foram construídas na produção e estrutura do conhecimento". Em sua argumentação, a autora afirma que o processo de formalização da prática científica em laboratórios e universidades restringiu o acesso das mulheres à ciência, uma vez que o acesso à universidade, em geral, não era permitido a elas. Assim, destaca que o poder da ciência ocidental "é celebrado por produzir conhecimento objetivo e universal, transcendendo as restrições culturais. Entretanto, no que diz respeito ao gênero, à raça e a muito mais, a ciência não é um valor neutro" (SCHIENINGER, 2008, p. 274).

Pesquisas realizadas por Maria Rosa Lombardi (2004), Raimunda de Nazaré Fernandes Corrêa (2011), Maria Celia Macedo Araújo Melo (2013), Adriana Zomer de Moraes (2016), Fabiane Ferreira da Silva (2012) e Liberato e Andrade (2018) problematizaram as relações entre as mulheres e as áreas de ciência e tecnologia. Mesmo desenvolvidas em diferentes tempos e espaços, os resultados apontam para a presença de mulheres em todas as chamadas áreas exatas, mas com distribuição desigual tanto na esfera acadêmica quanto no mercado de trabalho. Isso indica que as construções discursivas sobre o campo científico e suas subdivisões são mais difíceis de serem modificadas ao longo do tempo, uma vez que fazem parte de um contexto social ainda bastante desigual. Porém, como apresentam Liberato e Andrade (2018), apesar de muitos obstáculos, cada vez mais mulheres cientistas tornam-se reconhecidas $e$ valorizadas em suas áreas de atuação. Recentemente, algumas histórias das trajetórias de mulheres com sucesso no campo científico passaram a circular na mídia, em especial nas redes sociais.

A pesquisa que realizamos emerge com o propósito de examinar como as mulheres consideradas bem-sucedidas nas áreas científicas narram a sua trajetória de sucesso. Apoiamos-nos nas produções de Jorge Larrosa (2008) que discutem as formas como as pessoas são constituídas por suas experiências, no interior de tramas discursivas, como as histórias que relatamos sobre a nossa trajetória acadêmica e profissional. $O$ autor afirma que a pessoa humana "se fabrica no interior de certos aparatos (pedagógicos, terapêuticos) de subjetivação" (LARROSA, 2008, p. 37). Poderíamos dizer que a mídia, ao criar e colocar em circulação diferentes enunciações, é um destes aparatos que faz parte da constituição das subjetividades das mulheres nas áreas de ciência e tecnologia.

Assim, na esteira de Larrosa (2008), narrar-se é uma forma de constituir-se enquanto sujeito, uma vez que esse processo não está inicialmente determinado, mas vai se gestando ao longo da vida. Nas palavras do autor: "a ideia do que é uma pessoa, ou um eu, ou um sujeito, é histórica e culturalmente contingente" (LARROSA, 2008, p. 40). Tomar as trajetórias de mulheres como objeto de análise pressupõe não as entender enquanto matérias jornalísticas neutras, mas fazendo parte de um discurso que constitui determinados sujeitos. Conforme Larrosa (2008), os discursos constituem os sujeitos que contam sobre si em diversos contextos (práticas pedagógicas, práticas médicas, práticas religiosas etc.).

Em termos metodológicos, acompanhamos as reflexões de Dagmar Meyer e Marlucy Paraíso (2012) a respeito das pesquisas em Educação amparadas em uma perspectiva pósestruturalista de inspiração foucaultiana. Nesses trabalhos, segundo elas, não há uma única metodologia a ser seguida, mas o entendimento de que os caminhos investigativos podem ser definidos e construídos ao longo do processo, com base nos problemas que emergem do campo empírico. As autoras entendem uma metodologia

como um certo modo de perguntar, de interrogar, de formular questões e de construir problemas de pesquisa que é articulado a um conjunto de procedimentos de coleta de informações - que, 
em congruência com a própria teorização, preferimos chamar de 'produção' de informação e de estratégias de descrição e análise (MEYER; PARAísO, 2012, p. 16).

Além disso, as pesquisas realizadas com base nesse registro teórico, como a que realizamos, são constituídas levando-se em consideração a noção de que, ao final do processo de investigação, não se chegará a um resultado definitivo nem a uma verdade única (MEYER; PARAÍSO, 2012). Isso decorre do entendimento de que "a verdade é uma invenção, uma criação" (PARAísO, 2012, p. 27), ou seja, é resultado de relações de poder que estabelecem, em cada momento histórico, o que é considerado verdadeiro. As investigações que se inscrevem no pensamento pós-estruturalista estão mais interessadas em entender como os fenômenos sociais se organizam, buscando "descrever e problematizar processos por meio dos quais significados e saberes específicos são produzidos, no contexto de determinadas redes de poder, com certas consequências para determinados indivíduos e/ou grupos" (MEYER, 2012, p. 51), do que em explicar o que é, de fato, o objeto de estudo em questão.

A parte empírica deste estudo envolveu a análise de enunciações a respeito das trajetórias de sucesso de mulheres no campo científico obtidas nas redes sociais, em especial o Facebook, a "rede mais popular e mais disseminada" que se impõe como uma "fonte privilegiada de informação aos estudiosos" (Lúcia AMANTE, 2014, p. 28). Neste contexto, Marcilene Forechi (2018) afirma que as redes sociais digitais disseminaram-se na sociedade, principalmente nos últimos cinco anos, tornando-se relevante para o compartilhamento de notícias, para difusão de ideias e denúncias, bem como mobilização e organização de movimentos sociais, tais como os feministas.

Para obter o material empírico, seguimos as publicações de fan pages, ou páginas, sobre a temática "mulheres de sucesso no campo científico". Selecionamos páginas brasileiras que, de forma recorrente, publicavam reportagens com esse tema, abordando os seguintes conteúdos: matérias de reconhecimento de descobertas científicas feitas por mulheres e divulgação de casos de mulheres bem-sucedidas nas suas carreiras ou que tiveram recentemente algum destaque acadêmico. Considerando esses critérios, as páginas escolhidas para acompanhar regularmente foram:

1) ELAS nas Exatas: consiste em uma parceria entre o Fundo ELAS, Instituto Unibanco, Fundação Carlos Chagas e ONU Mulheres para reverter uma certa tendência de as mulheres escolherem as ciências humanas como área de atuação profissional.

2) Meninas Olímpicas: projeto que busca o empoderamento de meninas para que elas sejam protagonistas por meio da participação em olimpíadas científicas.

3) Parent in Science: grupo que surgiu com o intuito de discutir sobre a maternidade (e paternidade) dentro do universo da ciência do Brasil.

4) Mulheres na Ciência: espaço para mulheres cientistas contarem suas histórias e discutirem sua posição no mundo científico.

O material empírico examinado nesse artigo emerge das fan pages acompanhadas que funcionavam como agregadoras de notícias sobre o tema e, ao mesmo tempo, propagadoras, compartilhando conteúdos produzidos por outras pessoas ou sites. Para examinarmos essas reportagens, acompanhamos as discussões de Michel Foucault (2004) e Rosa Maria Bueno Fischer (2001) sobre a análise do discurso. Como aprendemos com o filósofo, os discursos não são expressões espontâneas dos indivíduos, mas constituídos conforme as regras de um determinado tempo que, por sua vez, dependem das relações de poder e saber que vão dar sentido e possibilidade àquilo que é expresso (FISCHER, 2001). Tendo esse entendimento, não buscamos verificar a legitimidade ou a veracidade das informações compartilhadas pelas páginas; consideramos a sua própria existência em circulação. Ou seja, o objetivo não foi buscar significados ocultos ou uma suposta verdade a ser revelada nas entrelinhas das reportagens, mas, sim, traçar um percurso de análise com o que se encontra na superfície, sem buscar uma relação de causa e efeito.

Ao final do processo de seleção do material, foram obtidas em torno de 20 notícias, divulgadas por meio de links, nessas páginas. A estratégia analítica utilizada envolveu três etapas. A primeira consistiu em selecionar todas as reportagens ou publicações encontradas nas páginas sobre mulheres bem-sucedidas na área científica. Na sequência, estivemos atentas para encontrar as recorrências e dispersões que se tornaram mais evidentes no material. $E$, por último, organizamos os excertos em séries para visualizar alguns dos sentidos presentes nas matérias selecionadas. O resultado desse exercício será descrito na próxima seção.

\section{Mulheres de sucesso no campo científico}

As matérias selecionadas para análise abordam a inserção de mulheres no campo científico, com destaque para as histórias produzidas pelas próprias mulheres. Importa destacar que as notícias referem-se a trajetórias tanto de jovens pesquisadoras, quanto daquelas com a carreira já consolidada. Em geral, apresentam elementos positivos dessas trajetórias, como 
a superação das dificuldades e o mérito acadêmico das entrevistadas. Os excertos abaixo evidenciam duas dessas narrativas:

\begin{abstract}
Atleta de cálculos, gaúcha de $\mathbf{1 4}$ anos se prepara para mundial
A gaúcha Mariana, 14, coleciona 11 medalhas em ciências exatas, incluindo uma de ouro na Obmep (Olimpíada Brasileira de Matemática das Escolas Públicas). Encontrou seu próprio método de estudo e chegou a acompanhar aulas em uma universidade federal como ouvinte. [...] Quer mostrar que as meninas são tão capazes de ter sucesso em matemática quanto os garotos. [...] Comecei do zero e descobri que sabia mais que alguns colegas que cursaram a sexta série. Eu temia não saber os conteúdos, mas fui percebendo que eu sabia. Eu não gosto de apenas ficar lendo. Gosto de ver vídeos e fazer resumos. Mas o método que eu descobri que funciona comigo é fazer provas simuladas. Eu adoro simuladas! Para estudar história, porém, prefiro ter aulas. É muito mais abrangente. [...] Eu desenvolvi o raciocínio lógico e conseguia simplificar os problemas na minha cabeça para resolvê-los. Depois da primeira medalha, comecei a descobrir sozinha outras olimpíadas (Paula SPERB, 2016, online).
\end{abstract}

\begin{abstract}
A sociedade espera que uma mulher tenha sonhos pequenos, mas eu decidi ser astronauta

Mylena Peixoto nasceu em Campos dos Goytacazes, no interior do Rio de Janeiro, tem 18 anos e visitou a sede da Nasa, no Texas (EUA) pela segunda vez em setembro. Na primeira experiência, em 2016, Mylena foi para os Estados Unidos depois de descobrir cinco asteroides ao participar de um programa internacional que mobilizou escolas públicas da sua cidade. [...] Você é jovem e ainda está no início da carreira, mas já teve grandes experiências que muitos cientistas só alcançam com mais tempo de estudo. Como você vê isso? Eu não diria que sou uma pessoa sortuda, porque eu batalhei muito para chegar aqui e com a ajuda de muitas pessoas. Mas eu me sinto privilegiada por ter tido a oportunidade de realizar um sonho tão grande. Hoje, meus sonhos ganharam o mundo! [...] me vejo representada nas histórias das vencedoras que se esforçaram tanto para alcançar reconhecimento (MULHERES NA CIÊNCIA, 2017, online).
\end{abstract}

Chama atenção, em todas as reportagens selecionadas, o fato de que as mulheres podem realizar grandes feitos acadêmicos, como ganhar diversas medalhas ou conhecer a National Aeronautics and Space Administration (NASA), nos Estados Unidos. A primeira questão que se coloca, então, é: por que essas conquistas precisam ser divulgadas? Uma explicação possível é que, culturalmente, as realizações acadêmicas nas áreas científicas não são naturalmente associadas às mulheres. Isso se deve, principalmente, pelas características relacionadas ao fazer científico e à cultura científica (SCHIEBINGER, 2008) que se constituíram historicamente vinculadas ao masculino. Ao mesmo tempo em que essa divulgação ocorre, também merece destaque o fato de que essas ações não estão estabelecidas como o padrão da presença feminina no campo científico, mas como exceção, reforçando o argumento de que há desigualdades de gênero na constituição do campo científico.

Assim, há um movimento de divulgar as realizações das mulheres em contraposição a décadas de silenciamento, onde esses feitos eram ignorados ou apropriados por outros atores, em geral masculinos (SCHIEBINGER, 2001). Isso corrobora a ideia de Luciana Luzzardi (2017, p. 27), ao observar que "quando uma mulher se destaca e tem visibilidade em áreas de trabalho dominadas por homens, há um esforço para entender e justificar tal êxito". Embora as matérias aqui apresentadas não abordem carreiras consolidadas, pois tratam de jovens mulheres inserindo-se em áreas de conhecimento onde a presença masculina é que predomina, é possível ver uma excepcionalidade ao descrever as realizações dessas mulheres, bem como uma busca por uma justificativa ao contar suas histórias de vida e hábitos escolares e acadêmicos, onde o esforço aparece como naturalizado.

A análise que empreendemos das reportagens sobre as histórias de sucesso de mulheres nas áreas da ciência e tecnologia evidenciou ressonâncias do imperativo da inclusão (Maura Corcini LOPES, 2009), mostrando que todos podem ter seu espaço nas carreiras científicas, inclusive as mulheres. Mas, que inclusão seria essa? Aqui, acompanhamos a discussão de Lopes (2009, p. 167) ao problematizar a inclusão a partir de uma perspectiva foucaultiana de governamentalidade:

Garantir para cada indivíduo uma condição econômica, escolar e de saúde pressupõe estar fazendo investimentos para que a situação presente de pobreza, de falta de educação básica e de ampla miserabilidade humana talvez se modifique em curto e médio prazo. A promessa da mudança de status dentro de relações de consumo - uma promessa que chega até aqueles que vivem em condição de pobreza absoluta -, articulada ao desejo de mudança de condição de vida, são fontes que mantêm o Estado na parceria com o mercado e que mantêm a inclusão como um imperativo do próprio neoliberalismo (LOPES, 2009, p. 167).

No caso das histórias das mulheres aqui examinadas, diríamos que se trata apenas de uma ressonância desse princípio no qual todos devem ter condições para estar inseridos na sociedade contemporânea e naquilo que ela valorize, como a área científica e tecnológica. 
Assim, se as profissões historicamente ocupadas por homens são as mais valorizadas, as enunciações presentes nas reportagens apontam para uma tentativa de mostrar que as mulheres também podem (e devem) estar incluídas. A divulgação de possibilidades para as mulheres, que até então não são vistas como naturais, poderia ser parte de uma lógica inclusiva. Lopes (2009) afirma que, ao vivermos em uma sociedade guiada por uma racionalidade neoliberal:

Todos devem estar incluídos, mas em diferentes níveis de participação, nas relações que se estabelecem entre Estado/população, públicos/comunidades e mercado. Não se admite que alguém perca tudo ou fique sem jogar. Para tanto, as condições principais de participação são três: primeiro, ser educado em direção a entrar no jogo; segundo, permanecer no jogo (permanecer incluído); terceiro, desejar permanecer no jogo (LOPES, 2009, p. 155).

As três condições de participação citadas acima estão conectadas e se fazem presentes nas histórias das mulheres examinadas neste artigo. A formação para ter condições de entrar no jogo passa por mecanismos que, segundo a autora, são mais educadores do que pedagógicos: "eles simplesmente educam a partir daquilo que mobilizam nos indivíduos" (LOPES, 2009, p. 156). No caso das estudantes descritas acima, essa mobilização se observa na expectativa de fazer parte do universo da ciência ativado por experiências não necessariamente escolares. Mylena, que visitou a Nasa, em um dado momento de sua narrativa, afirmou: "Quando estive lá, tive a certeza de que era aquilo que eu queria. Foi quando vi a minha paixão pela Ciência concretizada". Já para Mariana, o fato de participar das Olimpíadas Brasileiras de Matemática das Escolas Públicas evidencia a entrada nesse jogo, ou seja, o vínculo e a participação em atividades relacionadas às carreiras científicas.

Por condições de permanecer no jogo, Lopes (2009) entende as diversas políticas de inclusão. Embora nenhuma política de equidade de gênero apareça de forma explícita no material selecionado para este trabalho, é possível estabelecer um paralelo com o fato de que as estudantes tiveram seu desempenho acima da média identificado por professores e isso, de alguma forma, modificou suas trajetórias. Mylena, por exemplo, foi selecionada para participar do projeto internacional de Astronomia pelo seu professor de Física, fato que possibilitou suas visitas ao centro espacial nos Estados Unidos: "Como eu vinha me destacando no colégio, um professor de Física começou a observar meu desempenho e interesse pela Ciência, então me selecionou para participar do programa internacional 'Caça aos Asteroides'”. A estudante Mariana foi incentivada por seus professores a participar das competições e a avançar na escola: "No quinto ano, a professora percebeu que eu tinha um ótimo desempenho e rapidez para aprender. Ela propôs, então, que eu pulasse o sexto ano".

Estas ações de professores a partir do desempenho escolar das estudantes podem significar que, talvez, sem esse impulso, as alunas não teriam traçado o mesmo caminho de destaques acadêmicos. Acerca da inclusão, Alfredo Veiga-Neto e Lopes (2007) afirmam que a "igualdade de acesso não garante a inclusão e, na mesma medida, não afasta a sombra da exclusão" (p. 958). Desta forma, não basta estar na escola para ter condições iguais de competir no contexto acadêmico das ciências exatas. Conforme mostram as histórias de Mylena e Mariana, a atuação dos professores e a forma como a escola incentiva (ou não) certas atividades podem ser determinantes da futura inserção das estudantes no campo científico e tecnológico.

No que se refere à intenção de permanecer competindo, Lopes (2009, p. 156) afirma que "é o desejo que faz com que ninguém fique de fora; é ele que mobiliza os jogadores a quererem que seus pares continuem jogando". Isso implica enfrentar as dificuldades que possam surgir, como no caso de Mylena, que: "precisou movimentar a cidade para conseguir apoio financeiro e realizar as duas viagens" e que pretende seguir a carreira científica mesmo sabendo dos problemas que poderá encontrar: "Eu acredito na educação e estou disposta a lutar por incentivos à ciência no Brasil, pois só ela é capaz de transformar vidas". O desejo por competir também se expressa na trajetória de Mariana que, depois de conquistar a primeira premiação, seguiu competindo já por conta própria, sem o auxílio explícito dos professores: "Depois da primeira medalha, comecei a descobrir sozinha outras olimpíadas".

O segundo conjunto de reportagens que compõem esta seção analítica aborda a outra face do que foi apresentado acima: são os casos das mulheres que já têm uma carreira consolidada na área de ciência e tecnologia, tendo ingressado nesse meio nas décadas de 1970 e 1980. As mulheres narraram suas trajetórias levando em conta as dificuldades pelas quais passaram desde a graduação e ao longo da carreira, mas com ênfase na superação dos obstáculos de diversas ordens.

Ao olhar para as carreiras de mulheres na área científica e tecnológica, é preciso considerar o que afirma Manoela Carpenedo (2011) acerca das relações de poder que constituem as sociedades e, dentro delas, as relações de trabalho. A autora pontua que "o mercado de trabalho pode ser considerado por si só generificado, caracterizado, sobretudo, pela norma do trabalhador masculino" (CARPENEDO, 201 1, p. 109). Tomar o mercado de trabalho 
como generificado significa, nesta perspectiva, entendê-lo como não sendo um espaço neutro em relação às diferenças de gênero, mas, sim, considerar que os discursos que estabelecem essas diferenças também constituem e reverberam as relações de trabalho. Carpenedo (2011) destaca que, historicamente, a inclusão das mulheres no mercado de trabalho não se deu acompanhada necessariamente de uma mudança qualitativa nas relações de trabalho. Assim, embora o número de mulheres presentes em carreiras de ciência e tecnologia tenha crescido, é importante considerar a forma como essa inserção ocorreu. As reportagens selecionadas abaixo evidenciam essa questão:

Primeira professora negra no ITA, Sônia Guimarães cobra igualdade para mulheres: "conservadorismo já não é mais capaz de nos parar"

Sônia Guimarães foi a primeira mulher negra professora no Instituto Tecnológico de Aeronáutica (ITA) de São José dos Campos. Ela entrou para a sala de aula do ITA quando as mulheres ainda não eram aceitas no vestibular da instituição militar mais tradicional do país. As roupas coloridas e a risada alta contrastam com os corredores silenciosos dos laboratórios e com as fardas azuis dos militares da instituição. Professora de física há 26 anos no ITA, ela também é pesquisadora na área - onde a presença feminina é ainda menor. [...] Era a primeira negra da instituição, que tinha um número pequeno de docentes mulheres. [...] "Eu sei dos números que eu represento e quero que outras mulheres olhem para mim e vejam que é possível. Eu combato todos os dias um cenário que contrasta de mim só por estar aqui, mas eu quero mais que isso" (Poliana CASEMIRO, 2018, online).

O próximo caso é a história de uma professora da área de exatas que enfrentou grandes dificuldades financeiras antes de ter uma carreira consolidada como pesquisadora na área da Química:

PhD em Química por Harvard, brasileira faz pesquisa de ponta com alunos no ensino médio

A fala doce, baixinha e de sotaque carregado já dá a pista. Aquela mulher de aparência frágil, de não muito mais do que um metro e meio, tem o dom de contornar obstáculos. De família pobre de Franca, no interior de São Paulo, a professora de Química Joana D'Arc Felix de Souza, de 53 anos, estudou em apostilas emprestadas e, muitas vezes, dormiu com fome quando morava em Campinas, onde fez graduação, doutorado e mestrado na Unicamp. De lá, bateu asas para os Estados Unidos, onde concluiu seu pós-doutorado na Universidade de Harvard, uma das mais prestigiadas do mundo. [...] - Cheguei a passar fome, mas decidi vencer pelos estudos. Meu pai dizia: para atingir seus objetivos, tem que passar pelo sacrifício. Quem não nasce em berço de ouro tem que arregaçar as mangas. Se você desistir, nunca vai chegar lá. E ela chegou (Flávia JUNQUEIRA, 2017, online).

O que se evidencia nessa matéria é a forma como narra a professora: alguém capaz de superar os obstáculos com tranquilidade, sem pensar em desistir ou rebelar-se contra eles. A docilidade faz com que Joana consiga superar as dificuldades em embates, como fica expresso já no início da matéria, que conta a história trazendo elementos afetivos: "A fala doce, baixinha e de sotaque carregado já dá a pista. Aquela mulher de aparência frágil, de não muito mais do que um metro e meio, tem o dom de contornar obstáculos". Aqui é possível estabelecer um contraponto com o caso anterior, de Sônia, que ri alto e contrasta com o silêncio, enquanto Joana fala baixo e contorna as dificuldades, configurando assim formas diferentes de inserção de mulheres no campo científico.

A notícia a seguir aborda a vida e a carreira de uma mulher que assumiu a direção de uma escola de engenharia brasileira, possibilitando trazer para a discussão o que poderia ser considerado um ponto alto destas trajetórias acadêmicas:

Mulher assume direcão da Poli-USP pela primeira vez em 124 anos. Liedi Bernucci, 59, chefiará uma das maiores escolas de engenharia do país

Ao chegar à sala de aula da Escola Politécnica da USP, em 1977, a estudante Liedi Bernucci, então com 19 anos, ouviu de um professor: "Mulher não deveria entrar na engenharia, porque o que elas querem é casar e acabam roubando a vaga de um homem". É verdade que Liedi se casou, tempos depois, e também "roubou a vaga" de um homem, por assim dizer: tornou-se a primeira mulher a assumir a diretoria da Poli, uma das principais escolas de engenharia do país, após 124 anos de chefia masculina. O episódio em sala de aula poderia ter feito a estudante desistir, mas Liedi seguiu o conselho da mãe: "A melhor resposta é seguir em frente". Com 59 anos, ela foi eleita nesta quarta-feira (7) para o cargo máximo administrativo da Poli, uma instituição com 452 docentes e mais de 8.000 estudantes. Apesar das "ofensas costumeiras", como ela descreve o machismo na universidade, Liedi não duvidava da sua capacidade. Era boa aluna, com notas altas, e isso bastava. "Sou engenheira e objetiva, acredito nos números. Eles falam. Se na comparação eu estava melhor, não tinha como falar que eu era burra." (...) "A vida era conturbada, com dois filhos pequenos, mais trabalho e estudo. Era raro mulher com filho pequeno trabalhar naquela época. Mas, olhando para trás, isso me fortaleceu. Eu tinha que organizar o meu tempo, me dividir em mil tarefas, e achar que ia dar certo. Me fez ser otimista." (Marina ESTARQUE, 2018, online). 
Liedi afirma que sua chegada ao cargo de diretora é importante para as demais alunas e engenheiras porque, no seu tempo de estudante, não havia para quem reportar qualquer problema relativo a gênero: "Eram todos homens. A mulher se calava, engolia em seco. E, se reagisse, era chamada de histérica, o que é pesadíssimo". Segundo Liedi, é simbólico que haja uma mulher dirigindo a Poli-USP, mostrando, com isso, que há espaço para mulheres em uma instituição "conservadora e tradicional", onde, a princípio, esse espaço pode ser difícil de conseguir. Neste sentido, uma mulher ocupando o cargo de direção seria uma possibilidade de ter um espaço de escuta mais receptivo às demandas sobre questões de gênero nesse âmbito.

Na trajetória de Liedi também está presente a questão da conciliação entre a vida pessoal e a carreira acadêmica, dinâmica esta que, muitas vezes, é difícil de organizar. Em seu relato, vemos que ela teve que se dividir entre o trabalho e a formação acadêmica e o cuidado dos filhos. Acerca da inserção das mulheres no mercado de trabalho, Carpenedo (2011) lembra que

essa inserção não é acompanhada muitas vezes pela diminuição das responsabilidades femininas dentro da esfera privada no que diz respeito ao trabalho reprodutivo, visto que a figura da mulher como a principal responsável pelos cuidados e reprodução da vida ainda continua fortemente consolidada (CARPENEDO, 201 1, p. 15).

As três reportagens apresentadas anteriormente sobre as mulheres bem-sucedidas nas áreas da ciência e tecnologia evidenciam suas formas de permanecer na carreira e de superar as dificuldades para construir uma carreira, formas essas vinculadas ao esforço individual e à autonomia para lidar com a competitividade. Pode-se entender que os obstáculos de ordem estrutural e cultural, como o preconceito de gênero e a falta de recursos financeiros, foram enfrentados de forma individual e não coletiva ou institucional, conforme se observa nos excertos a seguir, extraídos das reportagens analisadas: "Apesar das 'ofensas costumeiras', como ela descreve o machismo na Universidade, Liedi não duvidava da sua capacidade"; "De família pobre (...) estudou em apostilas emprestadas e, muitas vezes, dormiu com fome quando morava em Campinas, onde fez graduação, doutorado e mestrado na Unicamp"; "A partir do momento que a gente não acredita no preconceito, conquistamos nossos objetivos"; "Temos que nos expor, dar a cara à tapa. Se você se dispõe a ser diretora de uma instituição tradicionalmente masculina, tem que encarar". Enfatiza-se a ideia de que os esforços árduos têm recompensas, como expressa Joana: "Cheguei a passar fome, mas decidi vencer pelos estudos. Meu pai dizia: para atingir seus objetivos, tem que passar pelo sacrifício".

Esta ideia que destaca e premia o esforço individual como forma central de atingir objetivos, a despeito de obstáculos estruturais, faz parte do que Foucault (2008) define como racionalidade neoliberal. Acerca dessa noção, Karla Saraiva (2014) afirma que

- liberalismo (e, posteriormente, o neoliberalismo também) é compreendido pelo filósofo como uma racionalidade que estabelece determinadas práticas. Essa racionalidade - que Foucault chama de governamentalidade -, ainda que possa aparecer de modo condensado nas formas de governar um Estado, atravessa toda a sociedade e implica em práticas de condução de condutas que extrapolam as ações estatais e se desdobram de modo muito mais amplo (p. 142).

Nesta perspectiva, a lógica neoliberal não fica restrita apenas às esferas governamentais ou do mercado, mas constitui práticas e funcionamentos em toda a sociedade. Um desses funcionamentos seria considerar a educação como um investimento, bem como a inclusão de todos como consumidores em algum grau, conforme abordado anteriormente por meio do imperativo da inclusão. Saraiva e Veiga-Neto (2009) afirmam, na esteira de Foucault, que a racionalidade neoliberal expressa uma diferença em relação ao liberalismo:

A governamentalidade neoliberal intervirá para maximizar a competição, para produzir liberdade para que todos possam estar no jogo econômico. Dessa maneira, o neoliberalismo constantemente produz e consome liberdade. Isso equivale a dizer que a própria liberdade transforma-se em mais um objeto de consumo (SARAIVA; VEIGA-NETO, 2009, p. 189).

Ainda de acordo com os autores, uma marca potente da racionalidade neoliberal relaciona-se à noção de que a liberdade de mercado e a competividade não são naturais, elas precisam ser estimuladas:

No neoliberalismo a ênfase se desloca para a concorrência. Uma concorrência que atravessa a sociedade em todos os seus níveis e em todas as esferas. Concorrência entre empresas, mas também entre indivíduos. Concorrência no âmbito dos assuntos considerados econômicos, mas também naqueles que estariam fora do estrito campo da economia (SARAIVA, 2014, p. 145).

A permeabilidade da competitividade na constituição dos sujeitos, neste caso, nas mulheres com carreiras consolidadas, é observável em algumas de suas falas, em que também 
é possível afirmar que o discurso da superação se articula com o discurso da competitividade. Liedi, por exemplo, ao enfrentar problemas com um professor, ainda na graduação, em um episódio que "poderia ter feito a estudante desistir", diz que "a melhor resposta é seguir em frente", ou seja, seguir no jogo. Na história de Joana, a superação fica mais evidente, e pode-se afirmar, a partir de sua fala, que as dificuldades não constituem uma razão forte o suficiente para deixar de competir e conquistar um espaço no campo científico, uma vez que ela, "estudando em apostilas emprestadas, passou nas três universidades estaduais de São Paulo: Unicamp, USP e Unesp". Além disso, segundo a matéria: "Joana conta sobre essa fase de sua vida sem nenhum traço de amargura". Dessa colocação, podemos destacar a resiliência e a flexibilidade, a capacidade de "contornar obstáculos", características que também fazem parte do discurso neoliberal, conforme indica Saraiva (2014):

Os corpos dóceis e adaptados a uma rotina sobre a qual eles não têm quase nenhuma ingerência já não servem para a empresa. Os trabalhadores agora devem ser proativos, autônomos e empreendedores. Os corpos dóceis devem ser substituídos por cérebros flexíveis (p. 147).

Acerca da competitividade inerente à racionalidade neoliberal, Carpenedo (2011) afirma que, ao mesmo tempo em que as políticas públicas para equidade de gênero são indispensáveis para mudanças de cenário, a concepção de igualdade refere-se, muitas vezes, ao fato de todos e todas estarem inseridos em um contexto de competição, mobilizando o discurso da meritocracia:

Jogar $\circ$ jogo da igualdade de oportunidades implica na necessidade de as mulheres responderem às demandas capitalistas exigidas pelo contexto contemporâneo às performances masculinas (isentas das funções de cuidado e da conhecida dupla jornada) para o sucesso no mundo do trabalho (CARPENEDO, 2011, p. 117).

As mulheres entrevistadas narram-se como vitoriosas, capazes de superar as dificuldades a partir de valores familiares ou de dedicação aos estudos. Sobre o ato de narrar-se, Larrosa (2008) afirma:

Aqui os sujeitos não são posicionados como objetos silenciosos, mas como sujeitos falantes; não como objetos examinados, mas como sujeitos confessantes; não em relação a uma verdade sobre si mesmos que lhes é imposta de fora, mas em relação a uma verdade sobre si mesmos que eles mesmos devem contribuir ativamente para produzir (p. 54).

Embora uma entrevista não se trate necessariamente de uma confissão, no sentido proposto por Larrosa (2008), ainda assim, coloca em circulação significados para as trajetórias que reverberam discursos. Desse modo, tanto a narrativa dos jornais quanto a autonarrativa das entrevistadas articulam-se em um processo de constituição de subjetividades, nas quais se evidencia a presença do discurso do empresariamento de si.

Nas falas das entrevistadas, tanto as que já têm uma carreira consolidada, quanto as que estão ainda no Ensino Médio ou nos primeiros anos da graduação/pós-graduação, está presente a ideia da autonomia, seja para trabalhar ou para estabelecer seus próprios métodos de estudo, como indicam os excertos abaixo: "Encontrou seu próprio método de estudos e chegou a acompanhar aulas em uma universidade."; "Estudar nunca foi uma obrigação. No começo, não era apaixonada por matemática, mas nunca tive dificuldade."; "No quinto ano, a professora percebeu que eu tinha um ótimo desempenho e rapidez para aprender. Ela propôs, então, que eu pulasse o sexto ano. (...) Foi por causa disso que virei autodidata."; "Já não preciso apenas do que o professor fala em sala de aula. Essa habilidade me ajudou muito na preparação para as olimpíadas de que participei."; "O método que eu descobri que funciona comigo é fazer provas simuladas."; "Eu desenvolvi raciocínio lógico e conseguia simplificar os problemas na minha cabeça para resolvê-los. Depois da primeira medalha, comecei a descobrir sozinha outras olimpíadas."; "A engenheira diz que não gostava muito da escola na infância - ela aprendeu a estudar com a irmã, que fez matemática na USP, no vestibular."; "Para eu ficar quietinha, minha mãe me ensinou a ler o jornal que chegava na casa. Sem estudo, minha mãe foi minha primeira professora. Ela só tinha até a $4^{a}$ série."; "A independência e autonomia agradam a cientista.".

A valorização da autonomia é uma característica importante da sociedade contemporânea, mobilizada pela racionalidade neoliberal que, como visto, constitui modos de ser que ultrapassam o âmbito econômico. Acerca desse tema, Saraiva (2014) afirma que a racionalidade neoliberal pretende estabelecer cada sujeito como empreendedor de si mesmo, ou seja, responsável pela sua própria inserção na sociedade de consumo. Ao apontar as mudanças nas relações de trabalho, que tendem para o que Saraiva (2014) chama de trabalho imaterial, essa autora observa as modificações ocorridas nos próprios sujeitos, no sentido de se constituírem como autônomos e flexíveis: "os corpos e os cérebros que o trabalho imaterial requer estão de acordo com esse princípio: já não priorizam a obediência a regulamentos, mas 
são geridos pelo próprio sujeito" (SARAIVA, 2014, p. 148). Assim, no processo de criação de novas formas de produzir e se relacionar com o trabalho, outras subjetividades entram em jogo para adequar-se ao novo funcionamento.

Segundo Sylvio de Sousa Gadelha Costa (2009), acompanhando este processo de mudanças na sociedade, houve uma expansão dos valores e ideias inicialmente presentes apenas no universo empresarial para os demais contextos sociais. Nas palavras do autor,

determinados valores econômicos, à medida que migraram da economia para outros domínios da vida social, disseminando-se socialmente, ganharam um forte poder normativo, instituindo processos e políticas de subjetivação que vêm transformando sujeitos de direitos em indivíduosmicroempresas-empreendedores (COSTA, 2009, p. 172).

Desse modo, segundo Costa (2009), estes funcionamentos empresariais não apenas se expandem como também passam a compor, normativamente, a subjetividade dos indivíduos, constituindo-os enquanto sujeitos empreendedores de si mesmos. Desde a perspectiva do empresariamento de si, é possível considerar que a educação e os processos de aprendizagem são centrais nesta nova configuração social. Esse entendimento, segundo Osvaldo Javier LópezRuiz (2004), é possível a partir da leitura da teoria do capital humano feita por Foucault. Esta noção de capital humano, consolidada nos Estados Unidos pelos economistas da Escola de Chicago na década de 1960, postula que a formação educacional dos sujeitos pode ser tomada como um investimento, que, se bem administrado, pode render frutos no futuro (LÓPEZ-RUIZ, 2004). Esse autor afirma, ainda, que a grande inflexão proposta pela teoria do capital humano é tornar o investimento em si próprio, enquanto capital, um processo desejado e compreendido por todos:

A ciência econômica, nesse caso, não cria só uma teoria sobre a economia; cria um repertório de interpretação que nos permite pensar e pensar-nos de maneira tal que não nos resulte repulsiva a imagem do humano como riqueza - como o havia sido em tempos de J. S. Mill. A partir de seus postulados "cientificamente verificáveis", o humano passa a ser entendido como uma forma de capital e, portanto, o "capital humano" e tudo o que se faça para incrementá-lo é investido de um valor positivo: cada pessoa deve - porque é economicamente conveniente, mas também porque é "moralmente bom" - aumentar suas habilidades, competências e destrezas a partir de "investimentos" constantes (LÓPEZ-RUIZ, 2004, p. 38).

Considerando a valorização do capital humano pela racionalidade neoliberal, Saraiva e Veiga-Neto (2009) afirmam que "o aprender a aprender significaria tornar-se empresário de si, colocando-se num processo de gestão daquilo que, segundo Foucault, é chamado de capital humano pelo neoliberalismo" (SARAIVA; VEIGA-NETO, 2009, p. 199). Dessa forma, as escolas, além de ensinarem saberes, ficam encarregadas de ensinar os sujeitos a investirem em si mesmos por meio da educação, já que "gerir seu capital humano é buscar estratégias de multiplicá-lo. À escola caberia ensinar essas técnicas de gestão" (SARAIVA; VEIGA-NETO, 2009, p. 199).

Reverberações desse discurso podem ser observadas nas falas das mulheres entrevistadas. Mariana, por exemplo, afirma que desenvolveu seu próprio método de estudos para as olimpíadas de que participa: "Já não preciso apenas do que o professor fala em sala de aula. Essa habilidade me ajudou muito na preparação para as olimpíadas de que participei". Sua autonomia para estudar é tanta que, segundo ela, precisa cada vez menos da escola para manter seu desempenho. O caso é emblemático ao mostrar o quanto a capacidade de aprender por conta própria e administrar a própria rotina de estudos é uma disposição que acompanha esses sujeitos ao longo da vida. Segundo lolanda Montano dos Santos e Viviane Klaus (2013, p. 64):

A forma contemporânea de viver requer um sujeito aprendente por toda a vida que pode recriar continuamente o seu eu ao se tornar um agente de resolução de problemas; um sujeito que seja responsável pelo progresso social e pela realização pessoal de sua própria vida, ou seja, um sujeito empresário de si, um sujeito 'gestor'.

Mariana afirma, ainda, o quanto a autonomia constituiu sua forma de construir conhecimento: "Eu desenvolvi o raciocínio lógico e conseguia simplificar os problemas na minha cabeça para resolvê-los. Depois da primeira medalha, comecei a descobrir sozinha outras olimpíadas". Assim como desenvolver o raciocínio lógico é uma habilidade valorizada na contemporaneidade, a capacidade de resolver problemas é uma habilidade-chave para o discurso do empreendedorismo de si, pois, contemporaneamente, são priorizados "enfoques que, em geral, promovem a iniciativa dos alunos, incentivando-os a fazer uma gestão de sua aprendizagem" (SARAIVA, 2014, p. 150). Neste sentido, os aprendizados não devem ser estanques, mas estarem a serviço de uma flexibilização das habilidades para a resolução de problemas.

As reportagens que compõem esta seção lançam o olhar para as diversas faces do que constituiria o espaço da mulher na área de exatas. As narrativas contam o caminho percorrido até o momento pelas entrevistadas, as dificuldades enfrentadas no contexto acadêmico e no mercado de trabalho, as mudanças ocorridas ao longo do tempo, as conquistas profissionais que ocorrem a despeito dos problemas, bem como as perspectivas de futuro. Pode-se afirmar 
que a mídia produz a relação entre mulheres e ciência, enfatizando as trajetórias de sucesso, com foco no indivíduo. Situa as mulheres não apenas como vítimas de processos discriminatórios, mas como resilientes e otimistas em relação ao futuro que depende, apenas, de si.

\section{Consideraçōes finais}

Finalizando o artigo, temos o propósito de apresentar algumas implicações do estudo para a área da Educação. Como esperamos ter apontado ao longo do texto, as discussões de gênero e ciência, na atualidade, não escapam à lógica neoliberal presente em nossa sociedade, com ênfase aos processos de inclusão, valorização do capital humano individual e do empresariamento de si. Como visto anteriormente, boa parte das estratégias de enfrentamento pelas mulheres dos problemas no campo científico se dá desde uma perspectiva individual e não coletiva. Cada mulher cientista encontra seu próprio caminho de superação, apesar de a discussão de gênero ser bastante publicizada nas redes sociais.

Nota-se, desse modo, o fortalecimento, ou o "empoderamento", de indivíduos e não de coletivos. Não cabe, aqui, um julgamento acerca das estratégias individuais ou coletivas como mais ou menos eficazes para combater as discriminações contra as mulheres. Entretanto, é importante salientar que o individualismo faz parte da racionalidade neoliberal que constitui a sociedade contemporânea, na qual a liberdade individual está conjugada com outros interesses (do mercado, por exemplo) e pode, portanto, ser problematizada. Como afirmam Santos e Klaus (2013, p. 71),

no mundo contemporâneo a "autonomia" dos sujeitos e das instituições (...), o aumento da "liberdade de escolha", a constituição de comunidades autogovernáveis - fragmentação social do todo social -, a proliferação dos discursos sobre o respeito e a tolerância para com a diversidade, as discussões sobre a equidade social e o avanço da democracia nos fazem acreditar que vivemos em uma sociedade mais "libertadora". Porém, somos cada vez mais regulados.

A realização desta pesquisa permitiu observar dois movimentos sendo produzidos pelas redes sociais a respeito da posição das mulheres no campo científico. O primeiro aponta que a emergência do debate sobre gênero e ciências está para além dos espaços acadêmicos ou militantes, relacionando-se com o compartilhamento de informações que as redes sociais possibilitam. Essa rede alimenta ainda mais o debate, ao mesmo tempo em que é alimentada pelo que ocorre "off-line". Esta circulação de enunciados é um dos movimentos que possibilita o rompimento de uma barreira invisível de silêncio, fazendo com que as informações sobre as condições de inserção das mulheres no meio científico e tecnológico cheguem a um número maior de pessoas. Com isso, esse movimento possibilita também que as mulheres encontrem outras pessoas em situações semelhantes, o que pode produzir encontros, tensionamentos e mudanças de conjuntura.

O segundo movimento diz respeito à presença do discurso do empresariamento de si nas narrativas e trajetórias das mulheres que se destacam na área das ciências exatas. Divulgar os casos de sucesso era uma ação recorrente nas páginas acompanhadas ao longo da realização desta pesquisa. O principal argumento para o compartilhamento de suas histórias é que elas podem servir como exemplo para outras mulheres, especialmente as mais jovens, que poderiam ver que existe espaço para elas nesse campo de trabalho. Porém, o que foi possível observar é que essas trajetórias são marcadas pelo enfrentamento individual - e, por vezes, solitário - das dificuldades para consolidar uma carreira e lidar com os preconceitos de gênero. Esse enfrentamento aparece no material analisado como uma superação positiva, que pode ser associada à racionalidade neoliberal em que o indivíduo é o único responsável por sua educação e qualificação profissional.

Desse modo, nas palavras de Zygmunt Bauman e David Lyon (2014, p. 132), as pessoas são estimuladas a buscar, sem muitas possibilidades de falhas, "soluções individuais para problemas socialmente gerados". Os autores ressaltam que a sociedade contemporânea institui os indivíduos de direito, mas que nem sempre isso se efetiva na prática, porque os problemas com que esses indivíduos se deparam apenas podem ter uma solução coletiva. Constitui-se, então, um sujeito em dívida com a solução desses problemas coletivos.

Portanto, propagar "casos de sucesso" em que a ênfase da narrativa é apenas na superação individual reforça este discurso meritocrático e enfraquece a coletividade que, a princípio, é necessária para realizar modificações culturais e estruturais na sociedade. A análise que realizamos não pretende minimizar os esforços individuais que constituem as trajetórias das mulheres apresentadas pelas reportagens, uma vez que a relação entre indivíduo e sociedade é bastante complexa. Não se trata, também, de afirmar que o empreendedorismo é algo apenas negativo, pois, embora seus possíveis efeitos não sejam objeto desta pesquisa, entendemos que a divulgação dessas histórias pode atuar, sim, como elemento catalisador de mudanças. 
Outro aspecto que se pode depreender da análise realizada neste trabalho e a partir dos apontamentos de Lyon (2014) é que a política não necessariamente acompanhou as modificações na sociedade contemporânea, veloz e global:

O poder agora existe num espaço global e extraterritorial, mas a política, que antes ligava interesses individuais e públicos, continua local, incapaz de agir em nível planetário. Sem controle político, o poder torna-se fonte de grande incerteza, enquanto a política parece irrelevante para os problemas e temores da vida das pessoas (LYON, 2014, p. 13).

Por isso, talvez, a ênfase atual seja nos movimentos virtuais, que dependeriam menos da políica, já que podem ser iniciados por um único indivíduo e provocar uma adesão e uma publicização extremamente rápidas, sem necessariamente ter uma pauta discutida coletivamente, o que, nas formas políticas tradicionais, levaria tempo. Não é objetivo deste trabalho produzir qualquer escrita prescritiva, porém, é importante que as iniciativas que buscarão enfrentar quaisquer discriminações, neste caso, discriminações de gênero no contexto científico e tecnológico, levem em consideração que talvez seja importante uma retomada do político e do coletivo enquanto formas de atuação na sociedade. Ainda a partir de Bauman e Lyon (2014, p. 133), temos que

as memórias 'quentes' que poderiam moldar e dirigir o desenvolvimento cultural de formas apropriadamente éticas são substituídas pela frieza de dedicar atenção ao e-mail recebido, à atualização do status e ao prognóstico revisado, enquanto eles voam pela nossa consciência.

O fluxo incessante de informações, segundo esses autores, tem a capacidade de diluir a memória do que é culturalmente produzido. Talvez a velocidade que caracteriza a internet e a sociedade contemporânea não dê tempo para que as memórias coletivas se tornem fortes. Por isso, não é evidente a continuidade dos movimentos virtuais de gênero, em que a viralização de um tópico suplanta o anterior no dia seguinte, sem que tenhamos condições de pensar em ações e análises mais demoradas sobre os diversos temas polêmicos que são compartilhados. Apesar disso, não se pode negar a efetividade desses mecanismos na disputa por espaço e voz. Como afirma Manuel Castells (2003, p. 11): "Nem utopia nem distopia, a internet é a expressão de nós mesmos através de um código de comunicação específico, que devemos compreender se quisermos mudar nossa realidade". Este artigo objetivou compreender alguns aspectos presentes nas redes sociais para, quem sabe, mudarmos nossa realidade.

\section{Referências}

AMANTE, Lúcia. "Facebook e novas sociabilidades: contributos da investigação". In: PORTO, Cristiane; SANTOS, Edmea (Orgs.). Facebook e educação: publicar, curtir, compartilhar. Campina Grande: Editora da Universidade Estadual da Paraíba, 2014. p. 26-46.

BAUMAN, Zygmunt; LYON, David. Vigilância líquida: diálogos com David Lyon. Rio de Janeiro: Zahar, 2014.

CARPENEDO, Manoela. Quando a resistência se torna política pública: analisando a produção de subjetividade(s) nas políticas de equidade de gênero no campo do trabalho. 201 1. Mestrado (Programa de Pós-Graduação em Psicologia Social) - Faculdade de Psicologia da Universidade Federal do Rio Grande do Sul, Porto Alegre, RS, Brasil.

CASEMIRO, Poliana. "Primeira professora negra no ITA, Sônia Guimarães cobra igualdade para mulheres: conservadorismo já não é mais capaz de nos parar". G1 Notícias [online], São Paulo, 08/03/2018. Disponível em https://gl.globo.com/sp/vale-do-paraiba-regiao/noticia/primeiraprofessora-negra-no-ita-sonia-guimaraes-cobra-igualdade-para-mulheres-conservadorismo-ianao-e-mais-capaz-de-nos- parar.ghtml. Acesso em 21/10/2019.

CASTELLS, Manuel. A galáxia da Internet: reflexões sobre a Internet, os negócios e a sociedade. Rio de Janeiro: Zahar, 2003.

CORRÊA, Raimunda de Nazaré Fernandes. Gênero, saber e poder: mulheres nas engenharias da Universidade Federal do Pará. 2011. Mestrado (Programa de Pós-Graduação em Desenvolvimento Sustentável do Trópico Úmido) - Núcleo de Altos Estudos Amazônicos da Universidade Federal do Pará, Belém, PA, Brasil.

COSTA, Sylvio de Sousa Gadelha. "Governamentalidade neoliberal, teoria do capital humano e empreendedorismo". Educação \& Realidade, Porto Alegre, v. 34, n. 2, p. 171-186, maio/ago. 2009.

ESTARQUE, Marina. "Mulher assume direção da Poli-USP pela primeira vez em 124 anos. Liedi Bernucci, 59, chefiará uma das maiores escolas de engenharia do país". Folha de São Paulo 
[online], 08/03/2018. Disponível em https://www1.folha.uol.com.br/cotidiano/2018/03/mulherassume-direcao-da-poli-usp-pela-primeira-vez-em- 124-anos.shtml. Acesso em 21/10/2019.

FISCHER, Rosa Maria Bueno. "Foucault e a análise do discurso em educação". Cadernos de Pesquisa, São Paulo, n. 114, p. 197-223, nov. 2001.

FORECHI, Marcilene. Identidades femininas em comentários no Facebook: uma análise a partir dos Estudos Culturais em Educação. 2018. Doutorado (Programa de Pós-Graduação em Educação) - Faculdade de Educação da Universidade Federal do Rio Grande do Sul, Porto Alegre, RS, Brasil.

FOUCAULT, Michel. Nascimento da Biopolítica. São Paulo: Martins Fontes, 2008.

FOUCAULT, Michel. A arqueologia do saber. Rio de Janeiro: Forense Universitária, 2004.

JUNQUEIRA, Flávia. "PhD em Química por Harvard, brasileira faz pesquisa de ponta com alunos no ensino médio". Jornal Extra [online], São Paulo, 25/09/2017. Disponível em https://extra.globo. com/noticias/rio/phd-em-quimica-por-harvard-brasileira-faz-pesquisa-de-ponta-com-alunos-noensino-medio-21863584.html. Acesso em 21/10/2019.

LARROSA, Jorge. "Tecnologias do eu e educação". In: SILVA, Tomaz Tadeu da. O sujeito da educação: estudos foucaultianos. Petrópolis: Vozes, 2008. p. 35-86.

LIBERATO, Tatiane Furukawa; ANDRADE, Thales Haddas Novaes de. "Relações de gênero e inovação: atuação de mulheres nos NITs paulistas". Revista Estudos Feministas, Florianópolis, v. 26, n. 2, ago. 2018. Disponível em https://periodicos.ufsc.br/index.php/ref/article/view/41763. Acesso em 11/09/2019.

LOMBARDI, Maria Rosa. Perseverança e resistência: a Engenharia como profissão feminina. 2004. Doutorado (Programa de Pós-Graduação em Educação) - Faculdade de Educação da Universidade Estadual de Campinas, Campinas, SP, Brasil.

LOPES, Maura Corcini. "Políticas de inclusão e governamentalidade". Educação \& Realidade, Porto Alegre, v. 34, n. 2, p. 153-169, maio/ago. 2009

LÓPEZ-RUIZ, Osvaldo Javier. O ethos dos executivos das transnacionais e o espírito do capitalismo. 2004. Doutorado (Departamento de Sociologia) - Instituto de Filosofia e Ciências Humanas da Universidade Estadual de Campinas, Campinas, SP, Brasil.

LOURO, Guacira Lopes. Gênero, sexualidade e educação: uma perspectiva pós-estruturalista. Petrópolis: Vozes, 2014.

LUZZARDI, Luciana. Força e luz: natureza, cultura e pedagogias de gênero na CEEE transmissão. 2017. Mestrado (Programa de Pós-Graduação em Educação) - Faculdade de Educação da Universidade Luterana do Brasil, Canoas, RS, Brasil.

LYON, David. "Introdução". In: BAUMAN, Zygmunt; LYON, David. Vigilância líquida: diálogos com David Lyon. Rio de Janeiro: Zahar, 2014. p. 9-24.

MELO, Maria Celia Macedo Araújo. Gênero e universidade: a presença da mulher aluna nos Cursos do Centro de Ciências Exatas e Tecnologia da Universidade Federal do Maranhão. 2013. Mestrado (Programa de Pós-Graduação em Educação) - Faculdade de Educação da Universidade Federal do Maranhão, São Luís, MA, Brasil.

MEYER, Dagmar Estermann. "Abordagens pós-estruturalistas de pesquisa na interface educação, saúde e gênero: perspectiva metodológica". In: MEYER, Dagmar Estermann; PARAísO, Marlucy Alves (Orgs.). Metodologias de pesquisas pós-críticas em educação. Belo Horizonte: Mazza Edições, 2012. p. 49-64.

MEYER, Dagmar Estermann; PARAÍSO, Marlucy Alves. "Metodologias de pesquisa pós-críticas ou sobre como fazemos nossas investigações". In: MEYER, Dagmar Estermann; PARAísO, Marlucy Alves (Orgs.). Metodologias de pesquisas pós-críticas em educação. Belo Horizonte: Mazza Edições, 2012. p. 17-24.

MORAES, Adriana Zomer de. Relações de gênero e a formação de engenheiras e engenheiros. 2016. Mestrado (Programa de Pós-Graduação em Educação) - Faculdade de Educação da Universidade do Sul de Santa Catarina, Tubarão, SC, Brasil. 
MULHERES NA CIÊNCIA. "A sociedade espera que uma mulher tenha sonhos pequenos, mas eu decidi ser astronauta". Mulheres na Ciência [online], 18/12/2017. Disponível em https://www. paramulheresnaciencia.com. br/noticias/sociedade-espera-que-uma-mulher-tenha-sonhospequenos-mas-eu-decidi-ser-astronauta-diz-jovem-brasileira-de-18-anos-que-visitou-nasa. Acesso em 21/10/2019.

PARAÍSO, Marlucy Alves. "Metodologias de pesquisas pós-críticas em educação e currículo: trajetórias, pressupostos, procedimentos e estratégias analíticas". In: MEYER, Dagmar Estermann; PARAÍsO, Marlucy Alves (Orgs.). Metodologias de pesquisas pós-críticas em educação. Belo Horizonte: Mazza Edições, 2012. p. 25-48.

SANTOS, lolanda Montano dos; KLAUS, Viviane. "A inclusão e o sujeito empresário de si". In: FABRIS, Elí Henn; KLEIN, Rejane Ramos. Inclusão e biopolítica. Belo Horizonte: Editora Autêntica, 2013. p. 61-78.

SARAIVA, Karla. "A aliança biopolítica educação-trabalho". Revista Pro-Posições, Campinas, v. 25, n. 2, p. 139-156, maio/ago. 2014.

SARAIVA, Karla; VEIGA-NETO, Alfredo. "Modernidade Líquida, Capitalismo Cognitivo e Educação Contemporânea". Educação \& Realidade, Porto Alegre, v. 34, n. 2, p. 187-202, maio/ago. 2009.

SCHIEBINGER, Londa. "Mais mulheres na ciência: questões de conhecimento". Revista História, Ciências, Saúde, Rio de Janeiro, v. 15, p. 269-282, jun./set. 2008.

SCHIEBINGER, Londa. O feminismo mudou a ciência? Bauru: Editora da USC, 2001.

SILVA, Fabiane Ferreira da. Mulheres na ciência: Vozes, tempos, lugares e trajetórias. 2012. Doutorado (Programa de Pós-Graduação em Educação em Ciências) - Faculdade de Química da Universidade Federal do Rio Grande, Rio Grande, RS, Brasil.

SPERB, Paula. "Atleta de cálculos, gaúcha de 14 anos se prepara para mundial". Folha de São Paulo [online], São Paulo, 21/02/2016. Disponível em https://wwwl.folha.uol.com.br/ educacao/2016/02/1741518-medalhista-de-matematica-gaucha-de-14-anos-estuda-paramundial.shtml. Acesso em 21/10/2019.

VEIGA-NETO, Alfredo; LOPES, Maura Corcini. "Inclusão e governamentalidade". Educação \& Sociedade, Campinas, v. 28, n. 100, p. 947-964, out./dez. 2007.

WALKERDINE, Valerie. "Ciência, razão e a mente feminina". Educação \& Realidade, Porto Alegre, v. 32, n. 1, p. 7-24, jan-jun. 2007.

Polliane Trevisan Nunes (pollianenunes@yahoo.com.br) é licenciada em Ciências Sociais e mestre em Educação pela Universidade Federal do Rio Grande do Sul. Atualmente, exerce funções pedagógicas e administrativas na Pró-Reitoria de Extensão da Universidade Federal do Rio Grande do Sul.

Fernanda Wanderer (fernandawanderer@gmail.com) é licenciada em Matemática pela Universidade Federal do Rio Grande do Sul, mestre e doutora em Educação pela Universidade do Vale do Rio dos Sinos. Professora permanente do Programa de Pós-Graduação em Educação da Universidade Federal do Rio Grande do Sul, vinculada à Linha de Pesquisa: Estudos Culturais em Educação. 


\section{COMO CITAR ESTE ARTIGO DE ACORDO COM AS NORMAS DA REVISTA}

NUNES, Polliane Trevisan; WANDERER, Fernanda. "Mulheres de sucesso no campo científico: uma análise de redes sociais". Revista Estudos Feministas, Florianópolis, v. 29, n. 2, e68120, 2021.

\section{CONTRIBUIÇĀO DE AUTORIA}

Polliane Trevisan Nunes: concepção, coleta de dados e análise de dados, elaboração do manuscrito, redação, discussão de resultados.

Fernanda Wanderer: concepção, elaboração do manuscrito, redação, discussão de resultados.

\section{FINANCIAMENTO}

Não se aplica.

\section{CONSENTIMENTO DE USO DE IMAGEM}

Não se aplica.

\section{APROVAÇĀO DE COMITÊ DE ÉTICA EM PESQUISA}

Não se aplica.

\section{CONFLITO DE INTERESSES}

Não se aplica.

\section{LICENÇA DE USO}

Este artigo está licenciado sob a Licença Creative Commons CC-BY 4.0 International. Com essa licença você pode compartilhar, adaptar, criar para qualquer fim, desde que atribua a autoria da obra.

\section{HISTÓRICO}

Recebida em 21/10/2019

Aceita em 30/10/2020 